\title{
Central Bank Communication Affects the Term-Structure of Interest Rates
}

\author{
Fernando Chague ${ }^{\dagger}$, Rodrigo De-Losso ${ }^{\ddagger}$, Bruno Giovannetti ${ }^{\S}$, Paulo \\ Manoel" $^{\text {I }}$
}

\author{
Contents: 1. Introduction; 2. The Optimism Factor; 3. Data; 4. OF and Future Interest Rates; 5. Robustness \\ Analysis; 6. Conclusion. \\ Keywords: Brazil, COPOM, Central Bank, Communication, Semantic, Term-structure of Interest Rates, \\ Monetary Policy, Optimism Factor. \\ JEL Code: $\quad$ E43, E52, E58, G12.
}

We empirically analyze how the Brazilian Central Bank (BCB) communication affects the term structure of future interest rates. Using principal components analysis, we construct a measure of the Monetary Policy Committee Minutes content that reflects policy makers optimism about the economic conditions. We call this measure the Optimism Factor (OF). When policy makers are more optimistic, reflected by increments in the OF, markets expectations respond and long-term future interest rates drop. Furthermore, when policy makers are pessimistic, reflected by a decrease in the OF, volatility on future interest rates increases. Our result indicates that policy maker communication has an effective impact on market expectations.

Analisamos empiricamente como as atas do Banco Central do Brasil (BCB) afetam a estrutura a termos da taxa de juros. Usando Análise de Componentes Principais, construímos uma medida do conteúdo dessas atas que reflete o otimismo dos gestores de política monetária em relação às condições economicas. Nomeamos essa medida de Fator de Otimismo (OF). Quando os gestores estão mais otimistas, de forma que o OF aumenta, as taxas de juros de longo prazo caem respondendo às expectativas de mercados. Além disso, quando os gestores estão pessimistas, de modo que o OF cai, a volatilidade das taxas de juros futuras aumenta. Nossos resultados sugerem que a comunicação dos gestores de política monetária tem um impacto efectivo nas expectativas do mercado.

\footnotetext{
*We would like to thank an anonymous referee, Gabriel Madeira, Ricardo Madeira, Carlos Eduardo Gonçalves, Fernando Botelho and Victor Westrupp for important comments and discussions.

${ }^{\dagger}$ Department of Economics, University of São Paulo. Av. Prof. Luciano Gualberto, 908, Cidade Universitária, Butatã, São Paulo. E-mail: fchague@usp.br

${ }^{\ddagger}$ Department of Economics, University of São Paulo. E-mail: delosso@usp.br

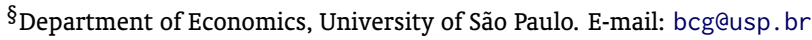

${ }^{\top}$ UC Berkeley Haas School of Business. E-mail: paulo_manoel@haas. berkeley.edu
} 


\section{INTRODUCTION}

In the recent scenario of low interest rates in the U.S. and in the Euro zone, the use of alternative monetary policy instruments has been an important research topic. As argued by Eggertsson and Woodford (2003) and Bernanke, Reinhart, and Sack (2004), a key ingredient in this context is the skillful management of agents' expectations through credible and clear central bank communication. In this work we provide empirical evidence that central bank communication has an effective impact on market expectations. We show that the content of the Brazilian Central Bank (BCB) minutes affects long-term interest rates and the volatility of future interest rates.

The effects of communication shocks in the level of interest rates are stronger on longer maturities. However, the effects of communication shocks in the volatility of interest rates are stronger on shorter maturities. Furthermore, positive and negative shocks also have different impacts on volatility. While the disclosure of minutes generally decreases volatility, a result pointed out by Costa Filho and Rocha (2010), the disclosure of a pessimistic minute actually increases volatility. In that sense, we extend the work of these authors by analyzing directly the economic content of the $\mathrm{BCB}$ minutes and not only the effect of their releases.

Our empirical strategy has two steps. In step one, we analyze the content of all minutes published by the BCB between 2000 and 2012. The minutes are released eight days after the monetary policy meetings (the COPOM meetings) take place. The minute, as in many other countries, is the most important instrument of monetary policy communication in Brazil. It contains an explanation for the chosen target for the basic interest rate (the SELIC rate) as well as an outlook on the economic conditions.

Our content analysis of the minutes follows an automated procedure. First, we classify words into predetermined semantic themes. For this task we use the Harvard IV dictionary, which maps words into semantic groups, such as "Positive", "Negative", "Strong", and others. Then we compute for each minute the relative frequency of each semantic group and use Principal Component Analysis (PCA) to extract factors from the time-series of such frequencies. The factor analysis suggests that a large portion of the information can be summarized by a single factor. The factor loadings and the correlations with macroeconomic variables indicate that this factor captures the optimism of the text about the economic conditions. We label this factor the "Optimism Factor" (OF). ${ }^{1}$

In step two of our empirical strategy we show that the market incorporates the information of the minutes into future interest rates contracts, particularly at longer maturities. We run regressions which have the changes of the yield curve on the day of the release of a minute on the left-hand side and the change of the $\mathrm{OF}$ as the explanatory variable. The estimates indicate that an increase of one standard deviation on the $\mathrm{OF}$ is followed by a decrease of 3 basis points ( $3 \mathrm{bps}$ ) per year in the 6-month future rate and a decrease of 5 bps per year in the 12- and 24-month future rates. These effects are economically important: the standard deviation of the daily change of the 12-month interest rate is $9 \mathrm{bps}$, while the average of the absolute value of this same variable is 5 bps.

A plausible concern is that our result may be contaminated by the changes in the SELIC rate. Indeed, a minute with a high OF should come along with a decrease in the SELIC rate, what would directly lower future interest rates. However, since the minutes are released more than a week after the monetary policy decision is made public, we are likely capturing the effect of the communication in isolation, as the changes in SELIC target rate are almost instantaneously incorporated into future interest rate contracts.

In fact, there is a growing literature trying to measure the relevance of communication by policymakers, and Blinder, Ehrmann, Fratzscher, Haan, and Jansen (2008) makes a comprehensive revision on that. They conclude that, although communication has the potential to move financial markets and to improve the predictability of monetary policy decisions, there are huge differences in communication strategies across central banks, resulting in a lack of consensus about what an optimal communication

\footnotetext{
${ }^{1}$ The OF series can be found in the NEFIN website http://http://www. fea.usp.br/nefin/ as COPOM Sentiment Factor.
} 
strategy should be.

Generally speaking the literature tries to infer the impact on asset prices like our paper and Rosa and Verga (2008). However, they make a subjective evaluation of the content of ECB statements. Following the same subjective method of measurement, Costa Filho and Rocha (2010) quantify the impact of the Central Bank minutes on interest rates in a manner we have tried to do.

Other articles measure the communication content indirectly to infer the impact of the minutes' releases on the volatility of the term structure of interest rates. That is the case of Janot and Mota (2012) and Caldas M. (2012), who use dummy variables for COPOM communication dates. The former authors find that the $\mathrm{BCB}$ minutes are able to reduce uncertainties about the interest rates future path, diminishing the volatility of the future interest rates after minutes releases, a result that we qualify better along this article.

Following a bit distinct path, Kohn and Sack (2003) and Reeves and Sawicki (2007) measure the impact of different central bank communication channels on asset prices. However, while the former authors do find evidence of impacts due to individual communications like the central bank chairman speech, the latter do not. Generally speaking, the communications reduces asymmetric information in the economy and therefore volatility of asset prices.

Our results are in line with the literature that shows that communication of the policymaker plays an important role on the pricing of interest rate claims. Boukus and Rosenberg (2006) provide evidence that the information content of the Federal Open Market Committee (FOMC) minutes can impact the Treasury yield around the time of the minutes release. Lucca and Trebbi (2009) show that long-horizon treasuries are more sensitive to changes in the Fed communication. Rosa (2011) shows that the European Central Bank had been successful in moving their domestic asset prices using communication shocks. Lamla and Lein (2011) show that long-horizon interest rates in the Euro zone are more sensitive to changes in the $\mathrm{ECB}$ communication.

Our paper is more related to Costa Filho and Rocha (2010) and Carvalho, Cordeiro, and Vargas (2013). The former authors also investigate how the $\mathrm{BCB}$ communication influences future interest rates. They find that the minute release reduces the volatility in the market. However, differently from us, they do not find evidence that the informational content of the minute drives future interest rates in the predicted direction. The latter authors find that changes in the informational content of COPOM statements affect the yields at short and medium maturities for the period prior to Tombini's tenure. However, they use an approach based on Lucca and Trebbi (2009), which is different from ours. In that sense, we believe that our results complement theirs and are arguably more reliable. We consider our work more reliable because it is simpler and because the BCB minutes are in English, without the need to adapt any Portuguese word to use the Harvard dictionary. So we keep a farther distance from subjective judgments on the meaning of words.

The rest of the paper is organized as follows. Section 2 describes the automated procedure to build the OF. Section 3 describes our data and provides some interpretation of our OF by correlating it with some macroeconomic variables. Section 4 analyzes the effects of the OF on the future interest rates. Section 5 presents robustness checks. Section 6 concludes.

\section{THE OPTIMISM FACTOR}

In June 1999 the Brazilian monetary authorities adopted an Inflation Targeting regime to set the basic interest rate (the SELIC rate) in the Brazilian economy that was largely inspired by the British model. In the Brazilian inflation target regime, the Brazilian National Monetary Council (CMN) deliberates the target for the SELIC rate on regular meetings (the COPOM meetings), which are held once every 6 weeks.

One important ingredient of every inflation target regime is the transparency. Eight days after each COPOM meeting, the committee releases the minutes summarizing the views of the Central Bank regarding the economic outlook and the explanation of the policy decision. These minutes are closely monitored by market participants. 
In order to assess empirically how market participants react to the minutes, we construct a timeseries factor that summarizes the word content in the minutes with numbers. In this section we present our methodology.

\subsection{Methodology}

There are two main approaches to quantitatively extract the content of a document. The first uses only the words in the document and the content is obtained from the correlations of the word frequencies (e.g. Boukus and Rosenberg 2006). The second uses auxiliary data to help determine the content of the document. An example of this approach is Lucca and Trebbi (2009) that uses the Google Search Engine to find the group of qualitative words that relate to the document's content. Another example of this approach is Tetlock, Saar-Tsechansky, and Macskassy (2008) that uses the Harvard IV dictionary to classify words according to their psycho-social meaning.

In this paper we follow the second approach and use the Harvard IV dictionary to quantitatively extract the content of the minutes. The dictionary classifies English words into 182 different semantic groups. The word "abandon", for example, is classified into the semantic groups "Negative", "Week" and "Fail". In our analysis we focus on the 18 most relevant groups, in terms of number of words that fall into them: "Positive", "Negative", "Pleasure", "Pain", "Feel”, "Arousal”, "Virtue”, "Hostile”, “Fail”, "Strong", "Weak", "Power", "Active”, "Passive”, "Work", "Try", "Persist” and "Complete".

The dictionary does not classify all inflected forms of words. For example, the dictionary may classify the word "connect", but does not classify the words "connected" or "connecting". In order to relate words that differ only due to inflections, we stem words using the algorithm proposed by Porter (1980). ${ }^{2}$ Table 1 shows the most frequent stemmed words in our sample of documents for each of the 18 semantic groups.

To obtain a quantitative measure of the documents content we proceed in the following way. First we group the $T$ documents (the COPOM minutes) in a collection denoted by $\left\{d_{1}, \ldots, d_{T}\right\}$. For each $t=1, \ldots, T$ let $v_{t}$ denote an $18 \times 1$ group-frequency vector of the document $d_{t}$, the vector whose $i$ th coordinate is the relative frequency of the stemmed words belonging to the semantic group $i$ in the document $d_{t}$. Next we use the vectors $\left\{\boldsymbol{v}_{1}, \ldots, \boldsymbol{v}_{T}\right\}$ to build a $T \times 18$ matrix $\boldsymbol{X}$ composed of 18 groupfrequency time-series. We define $Z$ as the matrix with the columns of $X$ demeaned and normalized. Defined in this way, the matrix $Z$ captures the unexpected changes in the content across documents.

Second, we summarize the available information in $\mathbf{Z}$ by using Principal Components Analysis (PCA). PCA does an orthogonal transformation of the data set into a new coordinate system such that the transformed time-series can be ranked by their explanatory power (measured by the contributions to total variance). Let $\mathbf{Y}$ denote the PCA projection of the data set $\mathbf{X}$. Figure 1 shows the portion of the variance associated with each column, i.e. factor, in $\mathrm{Y}$ in a descending order. We will use the first factor, which has by far the largest variance, to summarize the information content in the COPOM minutes.

\section{DATA}

Our sample consists of 130 minutes issued between 2000 and 2012. Up to 2005, the COPOM meeting were held once every month, and so in this period we have one minute per month. After 2005, the meeting were held less frequently but regularly spaced, and so in this period we have 8 minutes per year.

We use financial and macroeconomic variables to interpret our factors constructed from the minutes. We use a measure of economic activity, the real GDP variation over the previous twelve months seasonally adjusted, and of expected inflation, which is the variation in the consumer price index IPCA over the

\footnotetext{
${ }^{2}$ The open code of Porter (1980) algorithm can be found in several different computer languages in the website http://tartarus .org/martin/PorterStemmer
} 
Table 1. MOST FREQUENT WORDS OF EACH SEMANTIC GROUP.

This table contains the most frequent (stemmed) words of each semantic group in all Central Bank minutes. Values in brackets represent relative frequencies, measured in basis points.

\begin{tabular}{llll}
\hline & \multicolumn{3}{c}{ Word Ranking (in frequency) } \\
Group & \multicolumn{1}{c}{$\mathbf{1}$} & \multicolumn{1}{c}{$\mathbf{2}$} & \multicolumn{1}{c}{$\mathbf{3}$} \\
\hline Positive & good $(41.2 \mathrm{bps})$ & respect $(30.6 \mathrm{bps})$ & consid $(23.8 \mathrm{bps})$ \\
Negative & decreas $(31.9 \mathrm{bps})$ & declin $(20.4 \mathrm{bps})$ & lower $(7.2 \mathrm{bps})$ \\
Pleasure & eas $(3.9 \mathrm{bps})$ & optimist $(0.4 \mathrm{bps})$ & resolv $(0.2 \mathrm{bps})$ \\
Pain & shock $(5.7 \mathrm{bps})$ & stress $(1.6 \mathrm{bps})$ & tension $(0.7 \mathrm{bps})$ \\
Feel & vigil $(0.6 \mathrm{bps})$ & option $(0.4 \mathrm{bps})$ & rigid $(0.1 \mathrm{bps})$ \\
Arousal & determin $(3.1 \mathrm{bps})$ & avers $(2.0 \mathrm{bps})$ & anticip $(1.9 \mathrm{bps})$ \\
Virtue & good $(41.2 \mathrm{bps})$ & capit $(19.0 \mathrm{bps})$ & real $(14.2 \mathrm{bps})$ \\
Hostile & sever $(4.5 \mathrm{bps})$ & exclus $(3.4 \mathrm{bps})$ & exclud $(3.0 \mathrm{bps})$ \\
Fail & delinqu $(5.4 \mathrm{bps})$ & default $(2.7 \mathrm{bps})$ & lag $(2.6 \mathrm{bps})$ \\
Strong & increas $(134.9 \mathrm{bps})$ & industri $(45.1 \mathrm{bps})$ & reach $(41.9 \mathrm{bps})$ \\
Weak & decreas $(31.9 \mathrm{bps})$ & averag $(27.1 \mathrm{bps})$ & declin $(20.4 \mathrm{bps})$ \\
Power & mai $(29.8 \mathrm{bps})$ & demand $(20.4 \mathrm{bps})$ & employ $(13.6 \mathrm{bps})$ \\
Active & increas $(134.9 \mathrm{bps})$ & reach $(41.9 \mathrm{bps})$ & oper $(32.1 \mathrm{bps})$ \\
Passive & growth $(36.4 \mathrm{bps})$ & expect $(32.2 \mathrm{bps})$ & decreas $(31.9 \mathrm{bps})$ \\
Work & adjust $(38.9 \mathrm{bps})$ & oper $(32.1 \mathrm{bps})$ & contribut $(16.2 \mathrm{bps})$ \\
Try & avail $(4.2 \mathrm{bps})$ & seek $(0.2 \mathrm{bps})$ & redeem $(0.1 \mathrm{bps})$ \\
Persist & continu $(23.1 \mathrm{bps})$ & maintain $(7.1 \mathrm{bps})$ & persist $(6.1 \mathrm{bps})$ \\
Complete & reach $(41.9 \mathrm{bps})$ & recoveri $(12.8 \mathrm{bps})$ & establish $(5.4 \mathrm{bps})$ \\
\hline
\end{tabular}

following twelve months. The financial variables we use are the Ibovespa stocks price index and the Brazilian Real / U.S. Dollar exchange rate.

We transform the macroeconomic and financial variables to have the same frequency of the COPOM minutes. For the variables that have lower frequencies, such as GDP growth and Consumer Prices (IPCA), we use the latest available observation. The variables that have higher frequencies, e.g. daily such as the exchange rate, we compute accumulated changes from the time one minute is disclosed to the following one.

\subsection{Interpreting the Factor}

Table 2 contains the factor loadings on the first factor. Higher weights are given to "Power" (with a negative sign) and "Positive" (with a positive sign). The other relevant weights are in "Virtue", "Pleasur", "Arousal", "Feel", with positive signs, and "Pain", "Fail" and "Hostile" with negative signs. The signs on the weights suggest an semantic interpretation of the resulting factor. Higher weights are given for words with positive, virtue, pleasure, arousal semantic content and lower weights are given on words with negative, pain, fail semantic content. Based on this observation we label this factor as the "optimism factor" (OF). We should emphasize, however, that this factor results from the PCA analysis - it is the factor that explains more of the variance. The fact that it may have some semantic interpretation is (in principle) a coincidence.

Figure 2 shows the evolution of the OF over time. First, we see a change of level around 2005. In the first five years, from 2000 to early 2005, negative changes in the OF were more often, while in the last 7 years, from 2005 and 2012, changes in the OF have been positive. In this period, the highest positive change in the OF occurred on December 2000, a period that coincided with low unemployment and controlled inflation. The two highest negative changes in the OF in this period occurred on May 2001 
Figure 1. PORTION OF THE VARIANCE CORRELATED WITH EACH FACTOR.

This figure graphs, in descending order of magnitude, the portion of the variance correlated with each factor in the PCA based on the matrix of the 18 semantic indexes extracted from the Central Bank minutes.

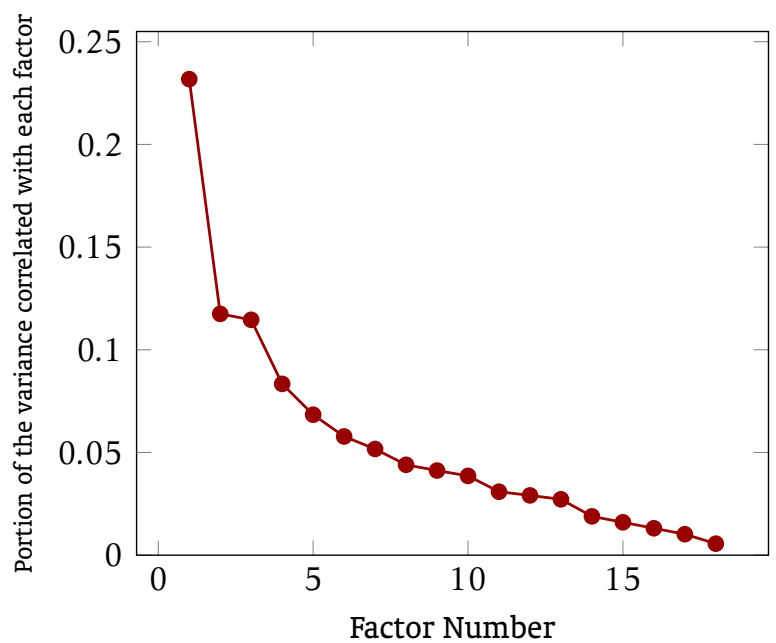

Table 2. LOADINGS ON THE FIRST FACTOR.

This table contains the weights by which each standardized original index should be multiplied to get the first factor. Weights are ordered by their absolute values.

\begin{tabular}{lr}
\hline Semantic Group & Weight \\
\hline Negative & -0.357 \\
Positive & 0.352 \\
Strong & 0.307 \\
Complet & 0.306 \\
Virtue & 0.297 \\
Work & 0.280 \\
Weak & -0.267 \\
Pleasur & 0.251 \\
Persist & 0.249 \\
Arousal & 0.223 \\
Feel & 0.212 \\
Pain & -0.210 \\
Passive & -0.138 \\
Power & -0.112 \\
Try & -0.096 \\
Active & 0.088 \\
Fail & -0.074 \\
Hostile & -0.065 \\
\hline
\end{tabular}


and July 2001, a time when the energy crisis was a major source of concern. On the last 7 years, the two lowest changes in the OF are in January 2009 and July 2012, which coincide with recessionary and poor growth periods that followed the subprime crisis and the euro-zone crisis.

The contemporaneous correlations of the factors with macroeconomic and financial variables in the Table 3 confirms the interpretation given to the Optimism Factor. The OF is positively correlated with GDP growth (0.39) and negatively correlated with the expected inflation $(-0.51)$. The OF is negatively correlated with the U.S Dollar/Real exchange rate variation $(-0.16)$, indicating that less optimist minutes and currency depreciation - an indication of higher prices-are related. Finally, the OF is positively correlated with the Ibovespa stocks index (0.09), although only slightly.

\section{OF AND FUTURE INTEREST RATES}

Future interest rates traded in the BM\&F Bovespa Stock Exchange provide a natural measure of investor's perception about future monetary policy decisions. In order to quantify such perception, we use six different contract maturities: one month, three months, six months, one year and two years. The data on futures contracts were obtained from the BM\&F Bovespa website. Table 4 shows some descriptive statistics.

\subsection{Effects in the Level of the Interest Rates}

Let $\{1,2, \ldots, T\}$ denote the set of COPOM meetings. $\Delta y_{t}^{m}$ is the variation of the future interest rate in the contract with $m$ months to maturity on the day the minute was released (i.e. in the closing price of the day the minute was released against the closing price one day before). We measure the shock in the communication from meeting $t$ as the variation in optimism factor with respect to its previous value observed at the $t-1$ COPOM meeting. That is, communication shock is measured by $\triangle O F=O F_{t}-O F_{t-1}$.

An important fact regarding the minutes is that they are released eight days after the new interest rate target is announced. This is important because when measuring the sensitivity of the future rates to shocks in the communication on the day the minute is released, we need not to control for the monetary policy decision and other related variables, as they should be already incorporated in the contract prices. By the same reason, the change in the COPOM meetings frequency has no effects in our results. In that sense, our following regressions resemble event study methods.

Let $\mathbf{m}=\left(m_{1}, m_{2}, \ldots, m_{n}\right)^{\top}$ denote the vector of maturities. We carry out the empirical analysis by running a linear regression model for $\Delta y_{t}^{m_{i}}$ against the optimism factor $\Delta O F_{t}$ :

$$
\Delta y_{t}^{m_{i}}=c_{i}+\beta_{i} \Delta O F_{t}
$$

for $i=1, \ldots, n$.

Table 5 contains the regression results for maturities equal to $1,3,6,12$, and 24 months, $\mathbf{m}=$ (1-month, 3-months, 6-months, 12-months, 24-months). The estimates show that a positive shock of one standard deviation to the optimism factor has the following effects: i) a decrease of one basis point on the three-month future rate, ii) a decrease of three basis point on the six-month future rate, and iii) a decrease of five basis point on the one- and two-years future rate.

The results indicate the following. First, increases in the interest rates are associated with pessimist minutes. This is coherent with the minute's content signaling concern with future inflation and driving investors to raise their forecasts on future changes in the interest rate. This result is line with the correlations shown in Table 3, as the optimism factor is highly correlated with expected inflation.

Second, in line with previous studies on monetary authorities communication (e.g. Lucca and Trebbi (2009) for the American case), we see that contracts with longer maturities are more sensitive to shocks in minute's content. This confirms the view that minutes contain information about future policy rate decisions and that market prices compounds this information on longer contacts. The general picture that can be drawn from the results in Table 5 is that the communication does affect market expectations 
Figure 2. TIME-SERIES OF THE FIRST FACTOR.

This figure graphs the time-series of the factor based on Central Bank minutes over the period from 2000 to 2012.

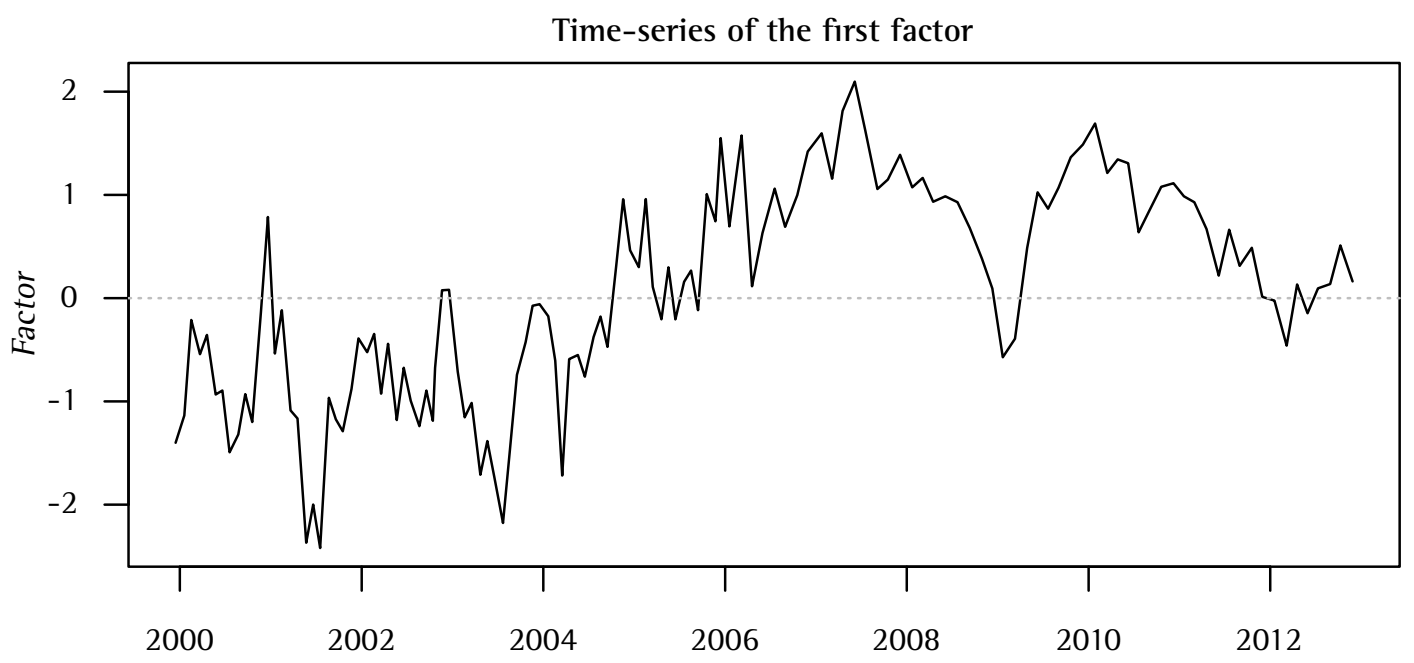

Table 3. SAMPLE TIME-SERIES CORRELATIONS.

This table contains the contemporaneous correlations between the optimism factor (OF) and four macroeconomic variables over the period from 2000 to 2012, with 129 observations. Macroeconomic variables are: i) SELIC, the monetary policy target rate; ii) INLF, the expected inflation measured by BCB inflation survey for the next twelve months; iii) GDP growth, measured by the inter meeting log-variation of the twelve months accumulated real GDP; iv) FX, the foreign exchange rate, measured by the intermeeting log-variation of the USD/BRL exchange rate; and v) IBOV, stocks returns measured by the intermeeting log-variation Ibovespa stocks index.

\begin{tabular}{lrrrrrr}
\hline & SELIC & INFL & GDP & FX & IBOV & OF \\
\hline SELIC & 1.00 & & & & & \\
INFL & 0.64 & 1.00 & & & & \\
GDP & -0.38 & -0.33 & 1.00 & & & \\
FX & -0.05 & -0.06 & 0.25 & 1.00 & & \\
IBOV & 0.07 & 0.04 & -0.19 & -0.62 & 1.00 & \\
OF & -0.64 & -0.51 & 0.39 & -0.16 & 0.09 & 1.00 \\
\hline
\end{tabular}

Table 4. DESCRIPTIVE STATISTICS OF THE FUTURE INTEREST RATES.

This table contains descriptive statistics for the sample of future rates with constant maturities. The data is from BM\&F Bovespa. Data from 03/01/2005 to 28/12/2012, 1967 observations.

\begin{tabular}{lccccc}
\hline & 1 month & 3 months & 6 months & 1 year & 2 years \\
\hline Mean & 12.29 & 12.25 & 12.24 & 12.34 & 12.63 \\
Median & 11.62 & 11.55 & 11.56 & 11.88 & 12.22 \\
Stdev & 3.37 & 3.34 & 3.24 & 3.03 & 2.62 \\
Min & 6.97 & 7.03 & 6.92 & 6.87 & 7.31 \\
Max & 19.82 & 19.88 & 19.74 & 19.42 & 18.78 \\
\hline
\end{tabular}


Table 5. REGRESSION RESULTS FOR FUTURE INTEREST RATES,

This table contains the estimates of the coefficients of the regression of the future interest rates changes (measured in basis points) against the changes in the optimism factor (OF) over the period from 2005 to 2012, with 68 observations. Changes in the future interest rate are the closing price on the day of disclosure of the minutes less the closing price one day before. Changes of the optimism factor are calculated as the difference of the OF between the contemporaneous minutes and the last minutes. Standard errors are in [square brackets].

\begin{tabular}{lccccc}
\hline & \multicolumn{5}{c}{ Dependent variable (estimates) } \\
\cline { 2 - 6 } Coefficient & $\begin{array}{c}\Delta \text { 1-month } \\
\text { yield }\end{array}$ & $\begin{array}{c}\Delta \text { 3-month } \\
\text { yield }\end{array}$ & $\begin{array}{c}\Delta \text { 6-month } \\
\text { yield }\end{array}$ & $\begin{array}{c}\Delta \text { 1-year } \\
\text { yield }\end{array}$ & $\begin{array}{c}\Delta \text { 2-years } \\
\text { yield }\end{array}$ \\
\hline$c$ & $0.09[0.16]$ & $-0.20[0.41]$ & $-0.03[0.76]$ & $-0.39[1.27]$ & $0.55[1.50]$ \\
$\Delta O F$ & $0.02[0.38]$ & $-0.75[0.82]$ & $-2.75[1.64]$ & $-4.80[2.14]$ & $-4.81[2.18]$ \\
$R^{2}$ & 0.00 & 0.01 & 0.03 & 0.04 & 0.03 \\
\hline
\end{tabular}

and in the direction predicted by its content. To the best of our knowledge, this is the first clean evidence that the $\mathrm{BCB}$ communication affects market expectations in the predicted direction (see Costa Filho and Rocha (2010) for an inconclusive result).

\subsection{Effects in the Volatility of the Interest Rates}

Janot and Mota (2012) and Costa Filho and Rocha (2010) show that the volatility of future interest rates are lower immediately after the disclose of the BCB minutes. In this Section we test how the content of the minutes influence the volatility of future interest rates.

Our measure of volatility at time $t$ on future contracts maturing in $m$ months is:

$$
\operatorname{Vol}_{5, t}^{m}=\sqrt{5^{-1} \sum_{i=0}^{4} \Delta y_{t+i}^{2}}
$$

where $y_{t}$ is the $m$-month maturity contract future interest rate in basis points. To test how the minutes content affects the volatility we run the following regressions:

$$
\begin{gathered}
\text { Vol }_{5, t}^{m}=\beta_{0}+\beta_{1} \cdot \text { minute }_{t}+\varepsilon_{t} \\
\operatorname{Vol}_{5, t}^{m}=\beta_{0}+\beta_{1} \cdot \text { minute }_{t}+\beta_{2} \cdot \text { pessimism }_{t}+\varepsilon_{t} \\
\log \left(\text { Vol }_{5, t}^{m}\right)=\beta_{0}+\beta_{1} \cdot \text { minute }_{t}+\beta_{2} \cdot O F_{t}+\varepsilon_{t} \\
\log \left(\text { Vol }_{5, t}^{m}\right)=\beta_{0}+\beta_{1} \cdot \text { minute }_{t}+\beta_{2} \cdot \text { OF }_{t}+\beta_{3} \cdot \text { pessimism }_{t} \cdot O F_{t}+\varepsilon_{t}
\end{gathered}
$$

where minute $_{t}$ is a dummy variable that takes a value of one on the day the minute is disclosed and

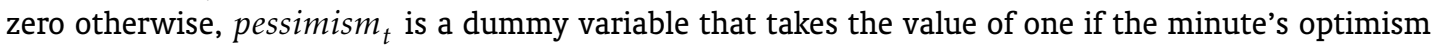
factor decreased and zero otherwise, and $O F_{t}$ is the optimism factor on days minutes are disclosed and zero otherwise.

Regression (2) is designed to capture the relation between future volatility and the disclosure of minutes, regardless of content. According to previous empirical works, we would expect volatility to decrease on the days that follow the release of the minute and so the coefficient $\beta_{1}$ should be negative. To this specification we add a dummy of pessimism in the regression (3) to allow for a different response depending on qualitative content of the minute. We expect the coefficient $\beta_{2}$ to be positive, as an increase in pessimism is typically related to higher uncertainty about the economic outlook and in the volatility of markets. 
In regression (4) we assess to which extent the magnitude of the shocks in the communication affect volatility. We use the natural logarithm transformation of the volatility to avoid the possibility of obtaining negative values for $\mathrm{Vol}_{5, t}^{m}$ as function of the explanatory variables at the right hand side. In regression (5) we allow for this relation between qualitative content and future volatility to be asymmetric. If we find that $\beta_{3} \neq 0$, we can conclude that pessimist and optimist minutes have different impacts on future volatility.

Table 6 contains the regression results of the 4 specifications for maturities of 3 months, 6 months, 1 year and 2 years. The estimated parameters in column (1) are in line with the findings of Costa Filho and Rocha (2010) and Janot and Mota (2012) that volatility decreases after the disclosure of the minutes. The parameters are negative and statistically different from zero for maturities up to 6 months. On longer maturities the parameters are still negative but not statistically significant.

The estimated parameters in the second column of Table 6 reveal that the disclosure of minutes has an asymmetric impact on volatility. Although on average the disclosure of minutes reduces volatility, when taking into account its content, we observe that minutes that bring pessimism actually increase volatility. The coefficients on the dummy for pessimistic minutes are positive for all maturities, and statistically significant on the regression with 6-months contracts. Also, when we include the pessimism dummy, the coefficients on the minute dummy turn out to be statistically different from zero at longer maturities. This shows that the content of the minute, particularly when it is optimistic, can also have a significant impact on the volatility of long maturity contracts.

The impact of the qualitative content of the minutes on volatility can also be seen when using the time-series of the OF instead of dummies. The estimates on the third column of Table 6 show that a negative shock of one standard deviation on the optimism factor (a pessimist minute) is followed by an increase of $27 \%, 30 \%, 21 \%$ and $18 \%$ in the log-volatility of the 3-months, 6-months, 1-year and 2-years contracts. The estimates on the fourth column show similar coefficients for the optimism factor and positive coefficients on minutes with negative content, although this asymmetry is not significantly different from zero.

We conclude that communication shocks, measured as changes in the qualitative content of the minutes, affects the level and the volatility of the future interest rates in different ways. The effects of communication shocks in the level of interest rates are stronger on longer maturities. However, the effects of communication shocks in the volatility of interest rates are stronger on shorter maturities. Furthermore, positive and negative shocks also have different impacts on volatility. While the disclosure of minutes generally decrease volatility, a result pointed out by Costa Filho and Rocha (2010), the disclosure of a pessimistic minute actually increase volatility.

\section{ROBUSTNESS ANALYSIS}

As a first robustness analysis exercise, we run the same regressions of section 3 but with changes in future interest rates one day prior to the disclosure of the minute as the dependent variable. Since the minute's content is not known beforehand, the OF should not have an effect on future interest rates unless there is a spurious relation. As expected, the results in Table 7 show that the estimated coefficients are not statistically different from zero.

In a second robustness exercise, we assess if the semantic classification of words are relevant to our results. For this purpose, we construct a factor based on a randomization of the Harvard IV dictionary. That is, we shuffle the dictionary categories in a random way and proceed to construct the factor following the same procedure. In our randomization of the dictionary, for example, the classification of the word "abolish" is substituted by the classification of the word "wild"; the classification of the word "accomplish" by that of the word "equate", and so on.

Table 8 contains the loadings of the factor constructed with the random dictionary. As we can observe, the optimism interpretation of the factor is no longer valid in this case. In fact, the resulting loadings do not allow for any clear interpretation as loadings on group of words with opposing semantic 
Table 6. REGRESSION RESULTS FOR THE FUTURE RATES VOLATILITY.

This table contains the estimates of the coefficients of the future interest rates volatility in a time window with five network days against some selected variables. The dependent variable is defined by $V o l_{5, t}=$ $\left(5^{-1} \sum_{i=0}^{4} \Delta y_{t+i}^{2}\right)^{1 / 2}$, where $y_{t}$ is the future interest rate measured in basis points; "minute" is a dummy with value 1 when the minute is issued and 0 otherwise; "pessimism" is a dummy with value 1 when the variation of the optimism factor is negative in comparison with optimism factor of the last minutes and 0 otherwise. OF is the optimism factor when the minute is issued and 0 otherwise. We use data over the period from 2005 to 2012 , with 2001 observations. The dummy "minute" and the variable OF have nonzero values in 68 observations, and the dummy "pessimism" have nonzero values in 33 observations.

\begin{tabular}{|c|c|c|c|c|}
\hline \multirow[b]{2}{*}{ Dep. variable } & \multicolumn{4}{|c|}{ Regression } \\
\hline & $\mathrm{Vol}_{5, t}$ & $\mathrm{Vol}_{5, t}$ & $\log \left(\operatorname{Vol}_{5, t}\right)$ & $\log \left(\operatorname{Vol}_{5, t}\right)$ \\
\hline \multicolumn{5}{|l|}{ Maturity: 3-month } \\
\hline Constant & $3.12[0.15]$ & $3.12[0.15]$ & $0.87 \quad[0.04]$ & $0.87 \quad[0.04]$ \\
\hline Minute & $-0.84[0.21]$ & $-1.00[0.26]$ & $-0.03[0.10]$ & $-0.04 \quad[0.10]$ \\
\hline Pessimism & & $0.33[0.36]$ & & \\
\hline Optimism Factor & & & $-0.27 \quad[0.10]$ & $-0.28 \quad[0.12]$ \\
\hline Pessimism $\times \mathrm{OF}$ & & & & $0.04 \quad[0.14]$ \\
\hline$R^{2}$ & 0.0030 & 0.0031 & 0.0051 & 0.0051 \\
\hline \multicolumn{5}{|l|}{ Maturity: 6-month } \\
\hline Constant & $4.51[0.21]$ & $4.51[0.21]$ & $1.26[0.04]$ & $1.26[0.04]$ \\
\hline Minute & $-0.54[0.33]$ & $-1.13[0.37]$ & $1.15[0.11]$ & $0.14 \quad[0.11]$ \\
\hline Pessimism & & $1.21[0.60]$ & & \\
\hline Optimism Factor & & & $-0.30 \quad[0.10]$ & $-0.31 \quad[0.10]$ \\
\hline Pessimism $\times \mathrm{OF}$ & & & & $0.07[0.15]$ \\
\hline$R^{2}$ & 0.0006 & 0.0015 & 0.0026 & 0.0027 \\
\hline \multicolumn{5}{|l|}{ Maturity: 1-year } \\
\hline Constant & $6.76[0.32]$ & $6.76[0.32]$ & $1.71[0.03]$ & $1.71[0.03]$ \\
\hline Minute & $-0.39[0.48]$ & $-1.02[0.53]$ & $0.14 \quad[0.11]$ & $0.14 \quad[0.11]$ \\
\hline Pessimism & & $1.31[0.87]$ & & \\
\hline Optimism Factor & & & $-0.21[0.10]$ & $-0.21 \quad[0.10]$ \\
\hline Pessimism $\times$ OF & & & & $0.01[0.16]$ \\
\hline$R^{2}$ & 0.0001 & 0.0006 & 0.0015 & 0.0015 \\
\hline \multicolumn{5}{|l|}{ Maturity: 2-years } \\
\hline Constant & $9.25[0.43]$ & $9.25[0.43]$ & $2.03[0.03]$ & $2.03[0.03]$ \\
\hline Minute & $-0.70[0.62]$ & $-1.41[0.63]$ & $0.12[0.08]$ & $0.12[0.08]$ \\
\hline Pessimism & & $1.46[1.13]$ & & \\
\hline Optimism Factor & & & $-0.18 \quad[0.08]$ & $-0.18 \quad[0.08]$ \\
\hline Pessimism $\times$ OF & & & & $0.01[0.15]$ \\
\hline$R^{2}$ & 0.0003 & 0.0006 & 0.0011 & 0.0011 \\
\hline
\end{tabular}


Table 7. REGRESSION RESULTS FOR PAST INTEREST RATES.

This table contains the estimates of the coefficients of the regression of the lagged (past) future interest rates changes (measured in basis points) against the changes in the optimism factor (OF) over the period from 2005 to 2012, with 68 observations. Changes in the future interest rate are the closing price one day before the disclosure of the minutes less the closing price two days before. Changes of the optimism factor are calculated as the difference of the $\mathrm{OF}$ between the contemporaneous minutes and the last minutes. Standard errors are in [square brackets].

\begin{tabular}{lccccc}
\hline & \multicolumn{5}{c}{ Dependent variable (estimates) } \\
\cline { 2 - 6 } Coefficient & $\begin{array}{c}\Delta \text { 1-month } \\
\text { yield }\end{array}$ & $\begin{array}{c}\Delta \text { 3-month } \\
\text { yield }\end{array}$ & $\begin{array}{c}\Delta \text { 6-month } \\
\text { yield }\end{array}$ & $\begin{array}{c}\Delta \text { 1-year } \\
\text { yield }\end{array}$ & $\begin{array}{c}\Delta \text { 2-years } \\
\text { yield }\end{array}$ \\
\hline$c$ & $0.53[0.25]$ & $-0.85[0.48]$ & $-1.48[0.60]$ & $-2.17[0.99]$ & $-2.67[1.19]$ \\
$\Delta O F$ & $-0.34[0.29]$ & $-0.76[0.46]$ & $-1.11[0.87]$ & $-1.16[1.13]$ & $-1.80[1.78]$ \\
$R^{2}$ & 0.01 & 0.01 & 0.01 & 0.00 & 0.01 \\
\hline
\end{tabular}

Table 8. FIRST FACTOR LOADINGS (RANDOM DICTIONARY).

This table contains the weights by which each standardized original index should be multiplied to get the factors (based on the random dictionary) values. Weights are ordered by their absolute values.

\begin{tabular}{lr}
\hline Semantic Group & Weight \\
\hline Hostile & 0.407 \\
Strong & 0.352 \\
Try & -0.337 \\
Negativ & 0.313 \\
Work & 0.272 \\
Arousal & 0.266 \\
Complet & 0.264 \\
Fail & 0.251 \\
Pain & 0.194 \\
Feel & 0.189 \\
Weak & -0.189 \\
Passive & 0.178 \\
Persist & -0.165 \\
Positive & 0.151 \\
Virtue & 0.130 \\
Active & -0.088 \\
Pleasur & 0.071 \\
Power & 0.031 \\
\hline
\end{tabular}


meanings show up with same signs.

Table 9 contains the estimates of the regression of the interest rates against this "fake factor", the factor based on the random dictionary. As expected, the coefficients are statistically insignificant at the level $10 \%$. This result points to the optimism factor not being related to an eventual spurious dynamic on the number of words, and that the meanings attached to the words by the dictionary plays a central role.

In our final robustness exercise, we check if future interest rate volatility responds incorrectly to shocks in the fake factor. We run the same regressions in section 4.2 but using the fake factor to construct the explanatory variables. Table 10 shows the results of regressing volatility of several contract maturities on a constant, a minute dummy (if on the day a minute was released), a fake pessimism dummy (if there was a negative variation in the fake factor), the fake factor (the value of the time-series when minutes are disclosed) and an interaction variable of the fake pessimism dummy and the value of the fake factor. As expected all the coefficients on the variables constructed using the fake factor are not statistically significant.

Our robustness analysis shows that the relation of the OF and future interest rates is not spurious, related to the mere number of words or some other mechanical aspect of our factor extraction procedure. The OF is likely to be capturing relevant information in the minutes that is taken into account by market participants and incorporated into future interest rates.

\section{CONCLUSION}

In this paper we objectively measure the impact of the Brazilian Central Bank (BCB) communication on future interest rates. For this purpose, we analyze the COPOM minutes (the Brazilian equivalent to the FOMC minutes) issued between 2000 and 2012 and propose a new method to measure the information content of the documents. Our method relies on the classification of words according to the semantic meanings and in the statistics of large data sets. The advantage of our methodology is that it is direct, without subjectivity in the interpretation of contents, and operationally simple.

We find that the information of the COPOM minutes can be summarized in a single factor. The analysis of factor loadings, as well as the correlations with economic and financial time-series, indicates that the factor is related to the optimism of the COPOM minutes about the economic outlook. We call our factor the optimism factor (OF).

Table 9. REGRESSION RESULTS FOR PAST INTEREST RATES.

This table contains the estimates of the coefficients of the regression of the future interest rates changes (measured in basis points) against the changes in the optimism factor based on the random dictionary over the period from 2005 to 2012, with 68 observations. Changes in the future interest rate are the closing price on the day of disclosure of the minutes less the closing price one day before. Changes of the optimism factor are calculated as the difference of the $\mathrm{OF}$ (based on the random dictionary) between the contemporaneous minutes and the last minutes. Standard errors are in [square brackets].

\begin{tabular}{lccccc}
\hline & \multicolumn{5}{c}{ Dependent variable (estimates) } \\
\cline { 2 - 6 } Coefficient & $\begin{array}{c}\Delta \text { 1-month } \\
\text { yield }\end{array}$ & $\begin{array}{c}\Delta \text { 3-month } \\
\text { yield }\end{array}$ & $\begin{array}{c}\Delta \text { 6-month } \\
\text { yield }\end{array}$ & $\begin{array}{c}\Delta \text { 1-year } \\
\text { yield }\end{array}$ & $\begin{array}{c}\Delta \text { 2-years } \\
\text { yield }\end{array}$ \\
\hline$c$ & $0.34[0.59]$ & $-0.82[1.15]$ & $-1.37[1.64]$ & $-2.45[2.01]$ & $-1.41[2.26]$ \\
$\Delta O F$ & $0.17[0.37]$ & $-0.43[0.67]$ & $-1.93[1.10]$ & $-1.43[1.56]$ & $-1.36[1.66]$ \\
$R^{2}$ & 0.00 & 0.01 & 0.01 & 0.01 & 0.00 \\
\hline
\end{tabular}


Table 10. REGRESSION RESULTS FOR THE FUTURE RATES VOLATLITY.

This table contains the estimates of the coefficients of the future interest rates volatility in a time window with five network days against some selected variables. The dependent variable is defined by $\operatorname{Vol}_{5, t}=\sqrt{5^{-1} \sum_{i=0}^{4} \Delta y_{t+i}^{2}}$, where $y_{t}$ is the future interest rate measured in basis points; "minute" is a dummy with value 1 when the minute is issued and 0 otherwise; "fake pessimism" is a dummy with value 1 when the variation of the fake factor is negative in comparison with fake factor of the last minutes and 0 otherwise. "FakeFactor" is the fake factor when the minute is issued and 0 otherwise. We use data over the period from 2005 to 2012, with 2001 observations.

\begin{tabular}{|c|c|c|c|c|}
\hline \multirow[b]{2}{*}{ Dep. variable } & \multicolumn{4}{|c|}{ Regression } \\
\hline & $\mathrm{Vol}_{5, t}$ & $\mathrm{Vol}_{5, t}$ & $\log \left(\operatorname{Vol}_{5, t}\right)$ & $\log \left(V o l_{5, t}\right)$ \\
\hline \multicolumn{5}{|l|}{ Maturity: 3-month } \\
\hline Constant & $3.12[0.15]$ & $3.12[0.15]$ & $0.87 \quad[0.04]$ & $0.87 \quad[0.04]$ \\
\hline Minute & $-0.84[0.21]$ & $-0.81[0.28]$ & $-0.22[0.14]$ & $-0.21 \quad[0.14]$ \\
\hline Pessimism & & $-0.05[0.35]$ & & \\
\hline Optimism Factor & & & $0.01[0.16]$ & {$[0.20]$} \\
\hline Pessimism $\times$ OF & & & & $-0.12[0.18]$ \\
\hline$R^{2}$ & 0.0030 & 0.0030 & 0.0033 & 0.0035 \\
\hline \multicolumn{5}{|l|}{ Maturity: 6-month } \\
\hline Constant & $4.51[0.21]$ & $4.51 \quad[0.21]$ & $1.26[0.04]$ & $1.26[0.04]$ \\
\hline Minute & $-0.54[0.33]$ & $-0.39[0.48]$ & $-0.10 \quad[0.13]$ & $-0.11[0.13]$ \\
\hline Pessimism & & $-0.34[0.60]$ & & \\
\hline Optimism Factor & & & $-0.05[0.18]$ & $-0.09 \quad[0.23]$ \\
\hline Pessimism $\times$ OF & & & & $0.06[0.20]$ \\
\hline$R^{2}$ & 0.0006 & 0.0007 & 0.0003 & 0.0004 \\
\hline \multicolumn{5}{|l|}{ Maturity: 1-year } \\
\hline Constant & $6.76[0.32]$ & $6.76[0.32]$ & $1.71[0.03]$ & $1.71[0.03]$ \\
\hline Minute & $-0.39[0.48]$ & $-0.29[0.68]$ & $-0.01[0.13]$ & $-0.01[0.13]$ \\
\hline Pessimism & & $-0.21[0.86]$ & & \\
\hline Optimism Factor & & & $0.00[0.17]$ & $0.03[0.23]$ \\
\hline Pessimism $\times$ OF & & & & $-0.04 \quad[0.20]$ \\
\hline$R^{2}$ & 0.0001 & 0.0002 & 0.0000 & 0.0000 \\
\hline \multicolumn{5}{|l|}{ Maturity: 2-years } \\
\hline Constant & $9.25[0.43]$ & $9.25[0.43]$ & $2.03[0.03]$ & $2.03[0.03]$ \\
\hline Minute & $-0.70[0.62]$ & $-0.56[0.87]$ & $0.09[0.10]$ & $0.09[0.10]$ \\
\hline Pessimism & & $-0.31[1.11]$ & & \\
\hline Optimism Factor & & & $0.13[0.14]$ & $0.17 \quad[0.17]$ \\
\hline Pessimism $\times \mathrm{OF}$ & & & & $-0.06[0.16]$ \\
\hline$R^{2}$ & 0.0003 & 0.0003 & 0.0003 & 0.0003 \\
\hline
\end{tabular}


We find that the variation of the future rates in a time window around the COPOM meeting respond to variations in the OF. Our results indicates that longer contracts reacts more intensively to changes in the communication, in line with the view that the minutes contain information about the future monetary policy actions and that market participants incorporate this information when pricing longer contracts.

We also find that the disclosure of minutes reduce the uncertainty, particularly at shorter horizons. On the days the minute is made public, the volatility of future interest rates is reduced. However, when we allow for an asymmetric impact by controlling for its content, the disclosure of pessimistic minutesdefined as the minutes associated with downturns in the OF-actually increase the volatility of future interest rates.

This paper contributes in two dimensions. First, it provides a procedure for extracting the content of documents that successfully capture the variation in the relevant information. Second, it provides evidence that market participants incorporate the information disclosed by $\mathrm{BCB}$ minutes.

\section{REFERENCES}

Bernanke, B. S., Reinhart, V. R., \& Sack, B. P. (2004). Monetary policy alternatives at the zero bound: An empirical assessment. Brookings Papers on Economic Activity, 35(2), 1-100. Retrieved from http://www.brookings .edu/ /media/Projects/BPEA/Fall-2004/2004b_bpea_bernanke.PDF

Blinder, A. S., Ehrmann, M., Fratzscher, M., Haan, J. D., \& Jansen, D.-J. (2008). Central bank communication and monetary policy: A survey of theory and evidence. Journal of Economic Literature, 46(4), 910-945. doi: 10.1257/jel.46.4.910

Boukus, E., \& Rosenberg, J. V. (2006, July). The information content of FOMC minutes (Tech. Rep.). Federal Reserve Bank of New York. doi: 10.2139/ssrn.922312

Caldas M., G. (2012). Financial market reaction to central bank monetary policy communications under an inflation-targeting regime: the case of Brazil. CEPAL Review, 107(Aug), 165-181. Retrieved from http:// www.cepal.org/publicaciones/xml/2/48672/RVI107Caldas.pdf

Carvalho, C., Cordeiro, F., \& Vargas, J. (2013). Just words? A quantitative analysis of the communication of the Central Bank of Brazil. Revista Brasileira de Economia, 67(4), 443-455. doi: 10.1590/S0034-71402013000400004

Costa Filho, A. E., \& Rocha, F. (2010). Como o mercado de juros futuros reage a comunicação do Banco Central? Economia Aplicada, 14(3), 265-292. Retrieved from http://www.scielo.br/scielo.php?script=sci _arttext\&pid $=$ S1413-80502010000300001

Eggertsson, G. B., \& Woodford, M. (2003). The zero bound on interest rates and optimal monetary policy. Brookings Papers on Economic Activity, 34(1), 139-233. Retrieved from http://www.brookings.edu/about/projects/ bpea/papers/2003/zero-bound-interest-rates-monetary-policy-eggertsson

Janot, M., \& Mota, D. E.-J. d. S. (2012, Jan). O impacto da comunicação do Banco Central do Brasil sobre o mercado financeiro (Trabalhos para Discussão No. 265). Banco Central do Brasil. Retrieved from http:// www.bcb.gov.br/pec/wps/port/TD265.pdf

Kohn, D. L., \& Sack, B. P. (2003). Central bank talk: Does it matter and why? (FEDS Working Paper No. 2003-55). Board of Governors of the Federal Reserve System (U.S.). doi: 10.2139/ssrn.483524

Lamla, M. J., \& Lein, S. M. (2011). What matters when? The impact of ECB communication on financial market expectations. Applied Economics, 43(28), 4289-4309. doi: 10.1080/00036846.2010.491452

Lucca, D. 0., \& Trebbi, F. (2009, September). Measuring central bank communication: An automated approach with application to FOMC statements (Working Paper No. 15367). National Bureau of Economic Research (NBER). doi: 10.3386/w15367

Porter, M. F. (1980). An algorithm for suffix stripping. Program, 14(3), 130-137. doi: 10.1108/eb046814

Reeves, R., \& Sawicki, M. (2007). Do financial markets react to Bank of England communication? European Journal of Political Economy, 23(1), 207-227. doi: 10.1016/j.ejpoleco.2006.09.018

Rosa, C. (2011). Talking less and moving the market more: Evidence from the ECB and the FED. Scottish Journal of Political Economy, 58(1), 51-81. doi: 10.1111/j.1467-9485.2010.00536.x 
Rosa, C., \& Verga, G. (2008, June). The impact of central bank announcements on asset prices in real time. International Journal of Central Banking, 4(2), 175-217. Retrieved from http://www.ijcb.org/journal/ ijcb08q2a5.pdf

Tetlock, P. C., Saar-Tsechansky, M., \& Macskassy, S. (2008). More than words: Quantifying language to measure firms' fundamentals. The Journal of Finance, 63(3), 1437-1467. doi: 10.1111/j.1540-6261.2008.01362.x 